\title{
Electrical properties of compacted carbon nanomaterials
}

\author{
Nikita I. Lapekin ${ }^{11}$, Artem A. Shestakov ${ }^{1}$, Andrey E. Brester ${ }^{1}$, Arina V. Ukhina ${ }^{2}$ and \\ Alexander $G$. Bannov ${ }^{1}$ \\ ${ }^{1}$ Novosibirsk State Technical University, 630073, Russian Federation \\ ${ }^{2}$ Institute of Solid State Chemistry and Mechanochemistry SB RAS, 630090, Russian Federation
}

\begin{abstract}
In this paper, the electrical properties of various compacted carbon nanomaterials were investigated. Compacted carbon nanomaterials (carbon nanofibers, multi-walled carbon nanotubes) were compacted into cylindrical samples and the electrical properties were measured in a frequency range from $50 \mathrm{~Hz}$ to $1 \mathrm{MHz}$.
\end{abstract}

\section{Introduction}

Nanostructured materials represent a new class of materials, which are of great scientific and practical interest. These materials make it possible to significantly improve the properties of so-called bulk 3D materials. Among the promising nanomaterials, carbon nanomaterials are studied extensively during last decades. They can be used in a lot of fields, such as catalysis, sensors, adsorption, etc. [1-3]. Carbon nanofibers (CNFs) and multi-walled carbon nanotubes (MWNTs) are very important objects, the electrical properties of which to be measured [4-6]. Usually, the electrical properties of such materials is hard to determine precisely, since they are all powders and their conductivity depends on the pressure applied on their bulk layer [5]. However there is one way to measure the conductivity of carbon nanomaterial powders is their compaction into pellets, tablets, which are easy to be measured.

There are several ways to measure the conductivity of materials without pre-pressing them. Such methods were proposed in [5,7]. The material is placed in a chamber made of insulating material and sealed with pistons, to which contacts are connected. However, this scheme is complex to implement, because it is necessary to use an insulator with high compressive strength for chamber.

Also, the electrical properties of carbon nanomaterials can be measured by means of obtaining papers. In $[5,9,10]$ the authors succeeded in obtaining MWNT paper by dispersing the material in surfactant solutions. However, preparation of papers is more time-consuming technique. This is due to the need to disperse the material's solution by ultrasound as well as subsequent filtration and drying. It should also be noted that it is difficult to obtain conductivity in this case, as it is not possible to obtain data on the geometric parameters of the papers.

\footnotetext{
${ }^{1}$ Corresponding author: bannov.alexander@gmail.com
} 
In this work, the conductivity of cylindrical compacts, tablets with a diameter of $10 \pm 0.2$ $\mathrm{mm}$ was investigated.

\section{Experimental}

Carbon nanofibers (diameter $80-100 \mathrm{~nm}$, obtained by CVD) and multi-walled carbon nanotubes (purchased by Shenzhen Nanotech Port Co., Ltd.) were compacted under pressure. Transmission electron microscopy (TEM) images of CNF and MWNTs are shown in Fig. 1.

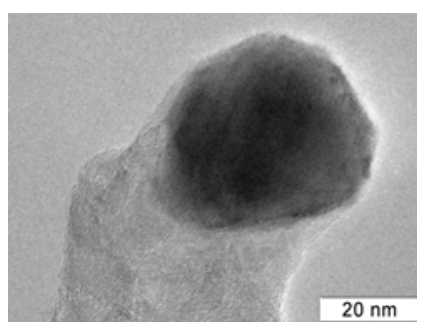

a)

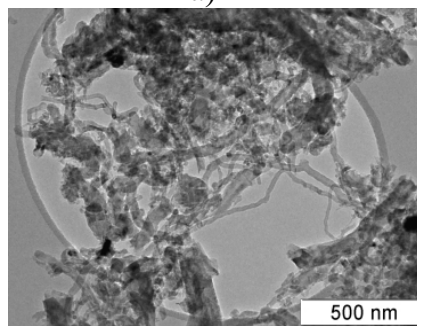

d)

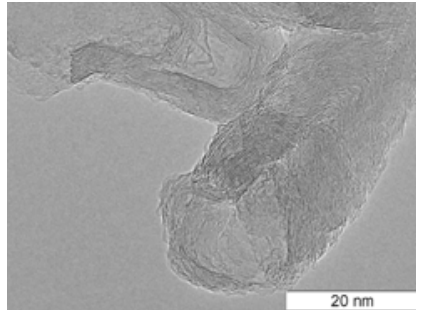

b)

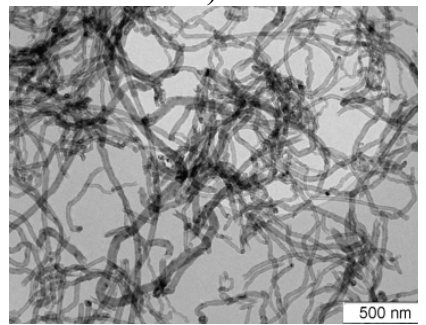

e)

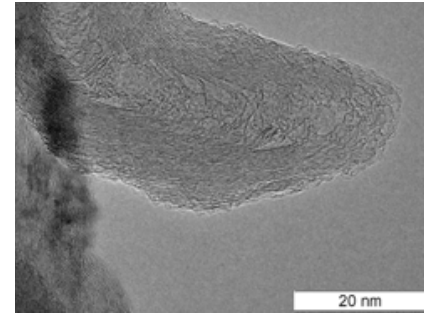

c)

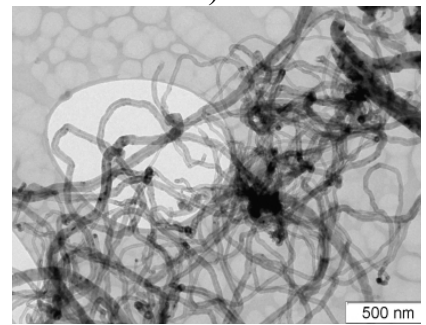

f)

Fig. 1. TEM micrographs of CNF (a, d), MWNT-1020 (b, e), MWNT-4060 (c, f) samples.

Tablets with a diameter of $10 \pm 0.2 \mathrm{~mm}$ were obtained. It was found that, it is necessary to select individual compaction parameters depending on the nature of material. Thus, the compaction pressure was $10 \mathrm{MPa}$ for MWNT-1020 and the compaction time was $16 \mathrm{~min}$. It has been determined that it is hard to carry out the compaction of granules of CNF samples. The pressure applied (10 MPa) and 20-min compaction was not enough to obtain a stable tablet sample without its destruction. CNF particles tend to appear their original shape and it complicates the CNF compaction significantly. It was found that it is not possible to obtain a compact from CNF sample without adding a binder. In [6] the elastic properties of CNFs were also investigated. Authors noted that an increase in pressure up to $7 \mathrm{MPa}$ leads to an increase in conductivity by $15-20 \%$, but after removal of the load the conductivity was restored to its original level. Thermally expanded graphite (TEG) was used as a binder. It was possible to compact CNF with TEG in a ratio of 4:1 (wt.) [8].

Samples of MWNTs were obtained without adding a binder. The electrical conductivity of the compacts was measured in a temperature range of $30-100{ }^{\circ} \mathrm{C}$.

The research was carried out in the cell shown in Fig. 2a. A sample of compacted carbon nanomaterials was placed in the cell made of polypropylene, fixed between the copper electrodes. A measuring cell was placed in the housing to which "Thermodat 13K5" PID controller was connected to control the temperature of sample heating. The scheme of the installation is shown in Fig. 2 b. 


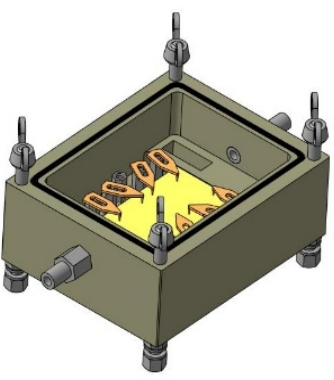

a)

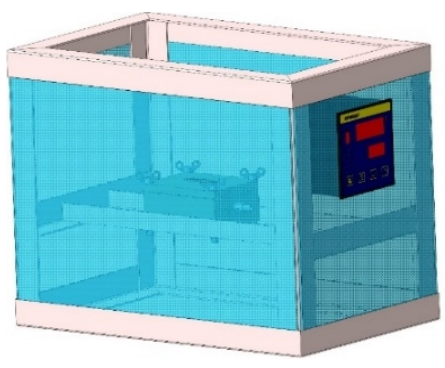

b)

Fig. 2. Scheme of installation for measuring the electrical properties of compacted carbon nanomaterials: $\mathrm{a}$ - measuring cell, $\mathrm{b}$ - housing of installation.

\section{Results and discussion}

The studies were carried out in a frequency range from $25 \mathrm{~Hz}$ to $1 \mathrm{MHz}$, according to a partially isothermal heating program from $30^{\circ} \mathrm{C}$ to $100{ }^{\circ} \mathrm{C}$. The curves of dependences of $\mathrm{AC}$ conductivity of samples on the frequency are shown in Fig. 3.

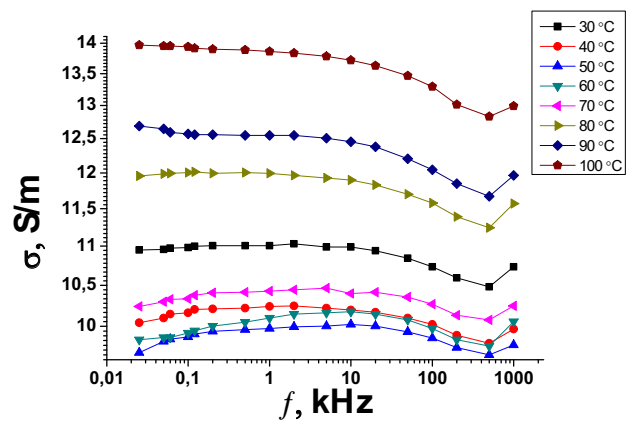

a)

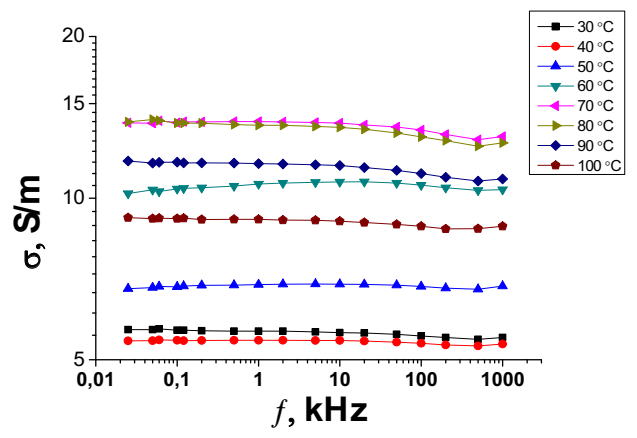

b)

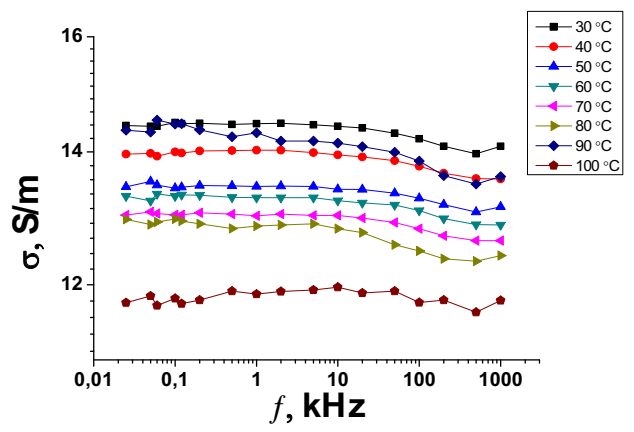

c)

Fig. 3. AC conductivity vs frequency of MWNT-1020 (a), MWNT-4060 (b), CNF/TEG (c) samples depending on the temperature $\left(30-100^{\circ} \mathrm{C}\right)$.

The graphs show that heating has a greater effect on the conductivity of MWNT samples compared to CNF/TEG system. This is presumably due to the structural features 
and defectiveness of the starting materials. When heating the MWNT-1020 sample from room temperature to $50{ }^{\circ} \mathrm{C}$, a decrease in conductivity from 11 to $9.5 \mathrm{~S} / \mathrm{m}$ was observed, however, upon further heating of the sample to $100^{\circ} \mathrm{C}$ an increase in conductivity up to 14 $\mathrm{S} / \mathrm{m}$ was found. The maximum conductivity was reached at the highest temperature. However, heating of the MWNT-4060 sample had the opposite effect compared to the MWNT-1020 sample: when heated to $70-80{ }^{\circ} \mathrm{C}$, an increase in conductivity from 5 to 14 $\mathrm{S} / \mathrm{m}$ was observed, but upon further heating, the conductivity decreased to $9 \mathrm{~S} / \mathrm{m}$.

Heating of CNF/TEG system did not have the same significant effect on conductivity as it was shown for MWNT-1020 and MWNT-4060 samples. The conductivity changed in a narrower range from 12 to $14 \mathrm{~S} / \mathrm{m}$. Variation of the AC frequency for the samples MWNT4060 and $\mathrm{CNF} / \mathrm{TEG}$ also has no effect on the conductivity of the materials over the entire heating range. However, it can be seen from the Figure 3 that for the MWNT-1020 sample, the frequency has some effect on the conductivity. At a temperature of $30-70{ }^{\circ} \mathrm{C}$, an increase in conductivity was observed in the frequency range $0.025-10 \mathrm{kHz}$, then the conductivity decreases with an increase in frequency up to $200 \mathrm{kHz}$, and then increased again afterward.

Since the AC conductivity of samples is almost independent on frequency, the conductivity at low frequency can be considered as DC conductivity. So, the DC conductivity of CNFs, MWNT-1020, and MWNT-4060 at room temperature was $14 \mathrm{~S} / \mathrm{m}$, $11 \mathrm{~S} / \mathrm{m}, 6 \mathrm{~S} / \mathrm{m}$, respectively. Comparing ratio of intensities $\mathrm{I}(\mathrm{D}) / \mathrm{I}(\mathrm{G})$ of bands of Raman spectra, which were $0.99,0.99$, and 0.55 . It can be suggested that such higher conductivity of CNFs compared to MWNT-1020 is caused by addition of binder, thermally expanded graphite, which has extremely high graphitization degree (99\%) and conductivity in its turn.

\section{Conclusions}

Compacts of carbon nanomaterials were prepared under pressure. Compacts of MWNTs could be compacted without the addition of binder, while compaction of CNFs requires a binder (e.g., thermally expanded graphite). It was found that heating has a greater effect on the conductivity of MWNT samples compared to the CNFs compacted with expanded graphite, which in turn may be due to the electron characteristics of the materials. It was also noted that the AC conductivity of the samples is practically independent on frequency, the conductivity at low frequency can be regarded as DC conductivity.

The work has been supported by the State Task of Ministry of Higher Education and Science (Grant No. FSUN-2020-0008).

\section{References}

1. T.K. Nguyen, A.G. Bannov, M.V. Popov, J.-W. Yun, A.D. Nguyen, Y.S. Kim, Int. J. Hydrogen Energ. 43, 17 (2018)

2. I.S. Berdyugina, Y.P. Steksova, A.A. Shibaev, E.A. Maksimovskii, A.G. Bannov, Russ. J. Appl. Chem. 89, 9 (2016)

3. A.G. Bannov, O. Jašek, A. Manakhov, M. Márik, D. Nečas, L. Zajíčková, IEEE Sens. J. 17, 7 (2017)

4. I.M. Alarifi, J. Mater. Res. Technol. 8, 5 (2019)

5. B. Marinho, M. Ghislandi, E. Tkalya, C. E. Koning, G. de With, Powder Technol. 221 (2012) 
6. I.V. Zolotukhin, I.M. Golev, A.E. Markova, S.N. Blinov, D.A. Grishin, É.G. Rakov, Tech. Phys. Lett. 31, 2 (2005)

7. K. Janerka, J. Jezierski, M. Stawarz, J. Szajnar, Materials 12, 4 (2019)

8. Y.P. Steksova, I.S. Berdyugina, A.A. Shibaev, A.V. Ukhina, E.A. Maksimovskii, M.V. Popov, A.G. Bannov, Russ. J. Appl. Chem. 89, 10 (2016)

9. J. Yu, K. Lu, E. Sourty, N. Grossiord, C. Koning, J. Loos, Carbon. 45, 15 (2007)

10. E. Tkalya, M. Ghislandi, A. Alekseev, C. Koning, J. Loos, J. Mater. Chem. 20 (2010) 